Georgia State University

ScholarWorks @ Georgia State University

\title{
Estimating the Associations between SNAP and Food Insecurity, Obesity, and Food Purchases with Imperfect Administrative Measures of Participation
}

Charles J. Courtemanche

Georgia State University, ccourtemanche@gsu.edu

Augustine Denteh

Georgia State University

Rusty Tchernis

Georgia State University, rtchernis@gsu.edu

Follow this and additional works at: https://scholarworks.gsu.edu/uwrg_workingpapers

\section{Recommended Citation}

Courtemanche, Charles J.; Denteh, Augustine; and Tchernis, Rusty, "Estimating the Associations between SNAP and Food Insecurity, Obesity, and Food Purchases with Imperfect Administrative Measures of Participation" (2018). UWRG Working Papers. 118.

https://scholarworks.gsu.edu/uwrg_workingpapers/118

This Article is brought to you for free and open access by the Usery Workplace Research Group at ScholarWorks @ Georgia State University. It has been accepted for inclusion in UWRG Working Papers by an authorized administrator of ScholarWorks @ Georgia State University. For more information, please contact scholarworks@gsu.edu. 


\section{W. J. Usery Workplace Research Group Paper Series}

Working Paper 2018-3-2

March 2018

Estimating the Associations between SNAP and Food Insecurity, Obesity, and Food Purchases with Imperfect Administrative Measures of Participation

Charles Courtemanche Georgia State University, NBER, Institute of Labor Economics

Augustine Denteh Georgia State University

Rusty Tchernis Georgia State University, NBER, Institute of Labor Economics 


\title{
Estimating the Associations between SNAP and Food Insecurity, Obesity, and Food Purchases with Imperfect Administrative Measures of Participation ${ }^{1}$
}

\author{
March 2018 \\ Charles Courtemanche ${ }^{2}$, Georgia State University, National Bureau of Economic Research, and \\ Institute of Labor Economics \\ Augustine Denteh, Georgia State University \\ Rusty Tchernis, Georgia State University, National Bureau of Economic Research, and Institute \\ of Labor Economics
}

\begin{abstract}
Administrative data are considered the "gold standard" when measuring program participation, but little evidence exists on the potential problems with administrative records or their implications for econometric estimates. We explore issues with administrative data using the FoodAPS, a unique dataset that contains two different administrative measures of Supplemental Nutrition Assistance Program (SNAP) participation as well as a survey-based measure. We first document substantial ambiguity in the two administrative participation variables and show that they disagree with each other almost as often as they disagree with self-reported participation. Estimated participation and misreporting rates can be meaningfully sensitive to choices made to resolve this ambiguity and disagreement. We then document similar sensitivity in regression estimates of the associations between SNAP and food insecurity, obesity, and the Healthy Eating Index. These results serve as a cautionary tale about uncritically relying on linked administrative records when conducting program evaluation research.
\end{abstract}

Keywords: Supplemental Nutrition Assistance Program, food stamps, SNAP, food insecurity, obesity, body mass index, food purchases, food expenditures, healthy eating index, misreporting, measurement error

JEL Codes: C81, H51, I12, I18

\footnotetext{
${ }^{1}$ This research was supported by USDA grant no. 59-5000-5-0115 to the National Bureau of Economic Research, entitled, "Using FoodAPS for Research in Diet, Health, Nutrition, and Food Security." The views expressed are those of the authors and not necessarily those of the Economic Research Service, Food and Nutrition Service, or the U.S. Department of Agriculture. We thank Marianne Bitler, Janet Currie, Christian Gregory, John Kirlin, Diane Schanzenbach, and participants at the Association for Public Policy Analysis and Management Fall Research Conference and National Bureau of Economic Research Conferences on Using FoodAPS for Research in Diet, Health, Nutrition, and Food Security for helpful comments.

${ }^{2}$ Corresponding Author. Department of Economics, Andrew Young School of Policy Studies, Georgia State University, Atlanta, GA 30302-3992.404-413-0082. ccourtemanche@gsu.edu.
} 


\section{Introduction}

A growing literature documents the problems with relying on survey measures of program participation, which suffer from significant reporting error, when conducting impact evaluations (Meyer, Mok, and Sullivan, 2015; Mittag, 2016; Nguimkeu et al., 2017). Administrative data are ordinarily assumed to be the "gold standard" to overcoming these econometric challenges, but relatively little evidence exists on the potential problems with administrative records or econometric strategies to address them. We investigate these issues using data from the FoodAPS, which combines a panel of household purchases with a survey and linked administrative data on Supplemental Nutrition Assistance Program (SNAP) participation from both state enrollment records and Electronic Benefit Transfer (EBT) card expenditures. The data, therefore, provide the unique opportunity to evaluate the reliability of administrative records by comparing the two different administrative measures to each other as well as to self-reported participation. Moreover, the data also allow us to examine the sensitivity of participation and misreporting rates and estimated associations between SNAP and food insecurity, obesity, and diet healthfulness to different approaches to cleaning and combining the administrative participation variables.

SNAP is the largest means-tested nutrition assistance program in the U.S., serving millions of low-income individuals and households. It is administered by the U.S. Department of Agriculture (USDA) with the objectives of increasing food security, reducing hunger, and improving health and well-being of low-income individuals and households by expanding access to food, nutritious diets, and nutrition education (Mabli et al., 2013). The number of Americans receiving SNAP benefits tripled from about 17 million to 46 million between 2000 and 2014, while total spending on SNAP has more than quadrupled from about $\$ 17$ billion to almost $\$ 75$ billion. $^{3}$

\footnotetext{
${ }^{3}$ Statistics are from http://www.fns.usda.gov/pd/supplemental-nutrition-assistance-program-snap.
} 
Proponents assert that SNAP participation reduces food insecurity, lifts millions from poverty, and provides a fiscal boost to the economy during downturns (U.S. Department of Agriculture, 2012). However, the empirical literature on the impacts of SNAP has produced mixed results. Several studies have documented the expected negative relationship between SNAP and food insecurity (Van Hook \& Ballistreri, 2006; Nord \& Prell, 2011; Schmidt et al., 2016), but others have found statistically insignificant or even positive associations (Gundersen \& Oliveira, 2001; Hofferth, 2004; Huffman \& Jensen, 2003; Wilde et al., 2005; Hoynes \& Schanzenbach, 2015). SNAP is also often found to be positively correlated with obesity, but some studies find insignificant or negative effects (Meyerhoefer and Pylypchuk, 2008; Gundersen, 2015; Almada et al., 2016; Almada \& Tchernis, 2016; Nguimkeu et al., 2017; Denteh, 2017).

These mixed results reflect two main methodological challenges in evaluating the causal effects of SNAP. The first is non-random selection. SNAP participation is endogenous, so there is a strong likelihood that specific unobservable characteristics are correlated with both SNAP participation and nutrition-related outcomes. Such factors might include current or expected future health, human capital, financial stability, and attitudes toward work (Currie, 2003; Kreider et al., 2012).

The second identification problem, and the focus of our paper, is measurement error in SNAP participation, which occurs when SNAP participants are coded as receiving no benefits when they truly did (false negatives) or vice versa (false positives). Misreporting of SNAP participation in national surveys has been documented with false negatives being much more prevalent than false positives. ${ }^{4}$ For instance, the estimated false negative rates for SNAP in various surveys range from 20\% to almost 50\% (Mittag, 2013; Meyer, George, and Mittag, 2015). There

\footnotetext{
${ }^{4}$ See Bound, Brown, and Mathiowetz (2001) for a comprehensive review of measurement error in survey data.
} 
is a growing literature suggesting that the estimated effect of a misclassified binary explanatory variable (such as SNAP participation) may be substantially biased and may even yield "wrong signs" (Kreider, 2010; Kreider et al., 2012; Nguimkeu et al., 2017). Within a one-sided model of endogenous misreporting, Nguimkeu et al. (2017) provide sign-switching results for the ordinary least squares (OLS) estimator even when participation is exogenous. In this case, they show that the OLS estimator yields the wrong sign if misreporting is endogenous, with the size of the signswitching region increasing with the rate of false negatives and decreasing with the true participation rate. ${ }^{5}$ Meyer and Mittag (2018) show that the likelihood of misreporting is syetematically related to observable characteristics such as income, employment, and geography, suggesting that is likely related to unobservable characteristics as well. Most researchers using survey data to study SNAP do not account for the possibility of non-classical measurement error and the few that do so make assumptions akin to random misreporting.

A fundamental difficulty in dealing with misreporting is that true participation status is unobserved in almost all surveys, and validation datasets that link survey responses to administrative records are scarce. Even when administrative data are available, their usefulness depends crucially on the quality of the linkage. While administrative data are usually considered the "gold standard," they can still be missing, incorrectly entered, or outdated. Some measurement error may therefore remain. By linking survey responses to administrative data on SNAP participation from two different sources, FoodAPS provides a unique opportunity to investigate issues related to measurement error in both self-reported and administrative measures.

Specifically, we use data from the FoodAPS to offer some novel insights related to the reliability of linked administrative SNAP measures. First, we document substantial ambiguity in

\footnotetext{
${ }^{5}$ Similar severe consequences of reporting errors also occur within an instrumental variables framework (Almada et al., 2016).
} 
both of the administrative measures and show that they are only slightly more strongly correlated with each other than with self-reported participation. Estimated SNAP participation and misreporting rates vary with the coding rules used to resolve this ambiguity and disagreement. We then examine the relationships between SNAP and food insecurity, obesity, and the Healthy Eating Index. While the signs of regression estimates are not sensitive to different coding rules, their magnitudes and levels of statistical significance exhibit meaningful variability. In sum, these results serve as a cautionary tale about uncritically relying on linked administrative records when conducting program evaluation research.

\section{Data}

The FoodAPS survey is the first nationally representative survey of U.S. households to collect comprehensive data about household food purchases as well as health and nutrition outcomes. FoodAPS is sponsored by the Economic Research Service (ERS) and the Food and Nutrition Service (FNS) of the USDA to support critical research that informs policymaking on health and obesity, food insecurity, and nutrition assistance policy.

The FoodAPS surveyed 4,826 households through a multistage sampling design with a target population roughly equally divided into SNAP households, non-participating low income households with income less than the poverty guideline, non-participating households with income between 100 percent and 185 percent of the poverty guideline, and non-participating households with income at least equal to 185 percent of the poverty guideline. ${ }^{6}$ Survey questions relate to demographic characteristics, income, program participation, food insecurity, health, weight, and

\footnotetext{
${ }^{6}$ The FoodAPS field operations were conducted from April 2012 through January 2013, during which each participating household provided information on all acquisitions of all household members during a 7-day interview period.
} 
height. Also, FoodAPS contains detailed information about individual food purchases and acquisitions (merged with nutrition information), along with variables related to local food availability and prices. A unique feature of FoodAPS that makes it well-suited for our study is the linked administrative records on SNAP participation for consenting respondents. This presents an opportunity to study SNAP misreporting more thoroughly than past research.

Participants were interviewed before they were given a survey to record their food purchases for one week. Self-reported SNAP participation comes from this initial interview. The primary respondent (PR) was asked about SNAP receipt, including information on the date of last receipt and the amount of benefits received. The PR was the designated "main food shopper" for the household. The specific question asking about SNAP participation states, "(Do you/Does anyone in your household) receive benefits from the SNAP program? This program used to be called food stamps. It puts money on a SNAP EBT card that you can use to buy food.” This question (named SNAPNOWREPORT on the FoodAPS data files) does not specify a reference period, and only respondents who answered "yes" were further asked to provide dates of the last receipt as well as benefit amounts received. Respondents who answered "no" were then asked, "Have (you/anyone in your household) ever received benefits from the SNAP program?" Households who responded in the affirmative to this follow-up question were further asked, "Did (you/anyone in your household) receive SNAP benefits in the last 12 months?" Respondents who answered "yes" to both follow-up questions were also asked to provide a date of the last receipt. ${ }^{7}$ For our indicator of reported SNAP participation (hereinafter "REPORT"), we consider all

\footnotetext{
${ }^{7} 66$ out of the 1461 people who answered "yes" to the first participation question subsequently reported date of the last receipt outside of the previous 31 days. Also, 8 out of 171 people who answered "no" to the first participation question but "yes" to both follow-up participation questions reported date of the last receipt within the previous 31 days. These reported dates of last receipt reflect the ambiguity about whether the initial participation question indicated current or recent receipt of SNAP. Our conclusions remain similar if we code these individuals as nonparticipants.
} 
respondents who answered "yes" to be self-reported participators (including those who answered "no" to the first participation question but "yes" to both follow-up questions), and consider the time-frame to reflect either current or recent participation. ${ }^{8}$ In our view, a flexible time-frame is reasonable, as our outcomes (particularly BMI, which is a capital stock) may not respond immediately to changes in benefit receipt, while people who have recently become nonparticipants may still spend down previously accrued benefits during the reference period.

The FoodAPS contains two distinct administrative measures of SNAP participation. The first is from state caseload files covering March 2012 to November 2012 (“ADMIN”). The second is from the electronic benefit transfer (EBT) ALERT database (“ALERT”). ${ }^{9}$ The ALERT transaction data contain one recorded swipe of an EBT Card per user from April through December 2012. FoodAPS is the only nationally representative survey that links reported SNAP participation to two administrative sources, thus making it particularly suitable for our purposes.

While such administrative records sound appealing, they have several limitations that likely lead to measurement error. ADMIN and ALERT contain various levels of missing data and do not always agree either with each other. The quality and availability of the administrative data vary considerably across states. Households can fall into one of four (4) state groups: (a) Group 1: one-to-one match was possible between ADMIN and ALERT data because they both contain the same case identifiers (13 states); (b) Group 2: either the CASEIDs in the ALERT data are scrambled or they are different in the ALERT and caseload data (8 states); (c) Group 3: CASEIDs are different in the caseload and ALERT data, and the former does not include benefit

\footnotetext{
${ }^{8}$ We thank John Kirlin for suggesting this modification to the original SNAPNOWREPORT via email correspondence.

${ }^{9}$ The EBT ALERT database is Anti-Fraud Locator EBT Retailer Transactions (ALERT) system of the Food and Nutrition Service (FNS) of the USDA designed to help detect signs of abuse, fraud, and waste in the SNAP program. Each record of the EBT ALERT data represents one swipe of the EBT card and includes such variables as information on the state, store ID, EBT account number, date/time of the event, and purchase amount.
} 
disbursement dates (2 states); and (d) Group 4: the state did not provide SNAP enrollment data (5 states).

Another source of measurement error is that matching from the FoodAPS to administrative SNAP records was probabilistic. All the matches to ADMIN data were based on first name, last name, phone number, and house address (including apartment number) and links were considered "certain matches" if the associated matching score exceeded a pre-determined threshold. ${ }^{10}$ The linkage to the ALERT data was similarly probabilistic, except in the state Group 1 described above. In state Group 1, if a household first matched probabilistically to caseload data, then a one-to-one match was possible to the ALERT data using CASEIDs. Thus, it is reasonable to presume that the quality of the administrative linkage would be highest in the 13 states in state Group 1. Nonetheless, the quirks of probabilistic matching would suggest unknown degrees of error in the administrative measures of participation in all states.

Additionally, the ADMIN and ALERT data may contradict each other because of discrepancies in timing. In the ADMIN data, participation is in most cases defined based on current enrollment status during the interview week. However, in the two states in Group 3 mentioned above, exact dates are not available; thus, their current participation status was conditional on the results of the EBT ALERT linkage. For instance, in a few cases, an individual is considered a current participant if they matched at any point during the nine-month data availability window and also matched to the EBT ALERT, with the date of the last receipt (per ALERT) within 36 days of the end of the survey week. ${ }^{11}$ Some former and future participants will therefore incorrectly be

\footnotetext{
${ }^{10}$ The probabilistic matching was implemented using LinkageWIZ record linkage software and resulted in a Cartesian join of each surveyed household with all SNAP enrolment record (or EBT ALERT). The contractors determined a pre-specified score above which to classify a match as "certain." FoodAPS does not contain the raw matching scores.

${ }^{11}$ FoodAPS's measure of current SNAP participation based on the two administrative linkages is summarized in the SNAPNOWADMIN variable, which combines the results of the two administrative matches into a single variable and also imputes missing data using the self-report.
} 
coded as current participants. The same logic applies to the EBT ALERT data. In the ALERT data, an individual is coded as a participant if she had an EBT card transaction during the survey week and matched to the EBT ALERT data. SNAP participants who did not use the EBT card that week - for instance, because they stocked up on groceries the previous week, or because their monthly benefits already ran out (food stamp cycling) - were coded as non-participants if they were also current non-participants per ADMIN. ${ }^{12}$

Another source of discrepancy regarding timing is that, while the ADMIN variable considers matches to represent current participation if the date of the last receipt is within 32 days of the end of the survey week, the ALERT variable uses 36 days of the end of the survey week. This may be related to the fact that the ALERT data do not have variables indicating the exact timing of deposits into the SNAP accounts. The ALERT issuance dates are approximate because issuance dates are determined by noting increments in the last SNAP balance between swipes. Thus, households classified as current recipients per ALERT may show up as current nonrecipients per the ADMIN variable due to the shorter window used by the latter. ${ }^{13}$

Finally, another issue with the ALERT data is that matches were not always attempted. For instance, no match was attempted if the respondent did not self-report SNAP receipt or any EBTtype payments. While most such individuals are likely true non-participants, this might not be the case for all of them. The high prevalence of false negatives reported in the literature tells us that some people incorrectly report not receiving SNAP, and it seems plausible that some of these same people would also not voluntarily disclose using an EBT card for any of their purchases. A match

\footnotetext{
${ }^{12}$ In the remainder (majority) of cases in the two states whose current SNAP participation cannot be determined based on EBT ALERT matching (conditional on ADMIN) or ADMIN (conditional on ALERT) due to missing information or non-matches, their current SNAP participation is coded as "no match" in SNAPNOWADMIN. ${ }^{13}$ This issue ceases to be relevant if we ignore the dates of the last receipt in classifying matches to the administrative sources, as we do in our baseline classifications discussed below.
} 
to EBT records was also not attempted if the individual reported SNAP participation but did not make a purchase at a SNAP-eligible store during the survey week. While some of these individuals may be genuine false positives, others might have simply not gone to the grocery store that week.

These issues create substantial ambiguity about the "correct" ways to code the administrative variables that we will explore in more detail in the following section. For now, we define the baseline versions of these two measures as follows. We set $A D M I N=1$ if there is a successful match to caseload records, even if the date of the match is outside of the previous month or missing. The rationale for the flexible timing mirrors that discussed above for the self-reported measure. We set $\mathrm{ADMIN}=0$ for individuals who did not match to the caseload records, and leave the variable missing for those in states that did not provide caseload records. For ALERT, we assign a value of 1 if there is a confirmed match (again, regardless of whether the match occurs during the survey month) and 0 if a match was attempted but unsuccessful. If no match was attempted, we set ALERT to missing.

Turning to a discussion of the other variables used in our analyses, our first two dependent variables relate to food insecurity. These come from the ten-question household food security questionnaire included in FoodAPS based on USDA's 30-day Food Security Scale. ${ }^{14}$ The specific outcomes are a dummy for whether the household has low food security (defined as having affirmative responses to three to five questions) and a dummy for whether the household has very low food security ( six or more affirmative responses).

The next several dependent variables relate to body weight. The FoodAPS contains selfreported height and weight for the household responder. We use this information to create three outcomes: body mass index (BMI) and indicators for obese $(\mathrm{BMI} \geq 30)$ and severely obese

\footnotetext{
${ }^{14}$ Please see the Appendix for the list of question on the ten-question household food security question.
} 
(BMI $\geq 35) .{ }^{15}$ Dichotomous variables are often used in addition to continuous BMI in the obesity literature since health is not monotonically decreasing in weight. Weight gain generally improves health at low levels of BMI, and the large increase in mortality risk from excess weight does not begin until around the severe obesity threshold (Courtemanche et al., 2016). The health implications of any impacts of SNAP would depend on the portion of the BMI distribution in which the effects are strongest (i.e., the health implications of SNAP's effects would potentially be more substantial if they are stronger on severe obesity).

The final dependent variable relates to food purchases. Following prior studies such as Volpe, Okrent, \& Leibtag (2013), we use a summary measure of the healthfulness of food purchases called the Healthy Eating Index (HEI). The HEI-2010, designed by the USDA, aims to capture the degree of adherence to dietary guidelines. We use the total HEI-2010 scores for all items for all the entire survey week for each household. ${ }^{16}$ The HEI score is made up of 12 components which sum up to a maximum score of 100 . This HEI variable is computed by FoodAPS staff and available as a linkable auxiliary dataset.

The FoodAPS also contains a number of variables that we use as controls. These include dummy variables for gender, educational attainment (dummy variables for having less than high school diploma, high school diploma but no college education, and some college education, with college degree or higher being the omitted base category), race/ethnicity (non-Hispanic black and non-Hispanic white, with other being the base category), marital status (married and formerly married, with never married as the base category), whether any individuals under 5 years old or at least 65 years old are present in the household, whether the respondent worked last week, whether the household lives in rural census tract, and whether the household's primary food store is SNAP-

\footnotetext{
${ }^{15}$ Body mass index is defined as weight in kilograms divided by height in square meters.

${ }^{16}$ Further information on HEI scores can be found at http://epi.grants.cancer.gov/hei.
} 
authorized. Continuous controls include respondent's age, household size, number of children, household monthly gross total income, and straight-line distance from household's residence to its primary food store (in miles).

Our "main sample" is subject to four restrictions. First, we include only households in which the primary respondent is at least 18 years old. Second, we drop households with missing values of any variables. Next, we follow Mykerezi and Mills (2010) and Almada et al. (2016) and drop those with incomes over $250 \%$ FPL. The final step is to exclude 122 households who did not provide consent for administrative verification. The resulting sample contains 2,108 households. The sample sizes in some of the sensitivity checks will vary, though, as we will experiment with different ways to handle ambiguous cases in the administrative SNAP variables.

Table 1 presents means and standard deviations for our main sample. The SNAP participation rate is 32 percent using the self-report compared to 29 percent with ADMIN and 30 percent with ALERT. The correlations between the three measures are 0.782 for REPORT and ADMIN, 0.792 for REPORT and ALERT, and 0.847 for ADMIN and ALERT. In other words, the two administrative measures exhibit almost as much disagreement with each other as either of them do with the self-reported measure. FoodAPS's primary respondents have an average BMI of 28.81, while 38 percent are obese and 16 percent are severely obese. About 20 percent of FoodAPS households are food insecure (low food security) while 13 percent experience very low food security. In terms of compliance with the U.S. Dietary Guidelines for Americans, FoodAPS households have an average HEI score of 50.56 out of a maximum score of 100; higher HEI scores indicate greater conformity with recommended dietary guidelines.

The primary respondents are on average, about 49 years old with a household size of about 2.56. Also, almost 71 percent of the primary respondents are female, 31 percent are married, 16 
percent are black, 71 percent are white, and about 38 percent report having worked last week. FoodAPS primary respondents have a gross monthly income of about $\$ 1,860$ and live in households with 26 percent holding college degrees or higher, 21 percent with some college education, 34 percent with a high school diploma, and 19 percent with less than high school diploma. Finally, 33 percent of FoodAPS household live in a rural census tract, 61 percent have children at most five years of age, and 28 percent have elderly at least 65 years present.

\section{Sensitivity of Participation and Misreporting Rates}

This section examines the sensitivity of SNAP participation and misreporting rates along two dimensions. The first type of sensitivity concerns different classification choices for the potentially ambiguous cases when continuing to use ADMIN and ALERT separately. The second is with respect to different approaches to combining ADMIN and ALERT into a single, "true" participation measure.

\section{A. Different Classification Choices for ADMIN and ALERT Separately}

The discussion of the SNAP variables in Section II revealed several challenges when coding ADMIN and ALERT. Tables 2 and 3 categorize the potential values of these variables to elucidate the specific sources of ambiguity. The tables also report the number of households in each category, how they are classified in the "baseline" classification used in Section II, and other reasonable ways in which they could be classified. The latter is given in the column names "Alternate 1" through "Alternate 3," wherein each column the specific categorization that differs from the baseline choice is in bold.

Focusing first on the ADMIN variable in Table 2, we see that there are five different broad categories a household can fall into. First is the straightforward case where the state did not make 
caseload records available, and therefore the ADMIN variable is clearly missing. The second category contains the most definitive non-participants: households who did not match to caseload records. Conceivably, someone could be a true participant but not match due to, for instance, name misspellings, or changes in household identifying information such as addresses and phone numbers. We expect such cases to be infrequent enough that exploring an alternate classification is not warranted, especially considering that some matches to the caseload data not deemed to be automatically "certain” were manually reviewed to address such concerns. Category 3 consists of the clearest participants: those who matched to caseload records within the 32 days before and including the survey week.

The final two categories are the most ambiguous. Category 4 contains households that matched to caseload records but with a date outside the 32-day window. As discussed in Section II, the intention of our baseline classifications is to measure either current or recent participation, in which case the most natural classification of these households is as participators. Moreover, a sizeable number of households show matches in both the months immediately before and after the survey month, but not in the survey month. In these cases, the lack of a match in the survey month is likely an error, and a determination of "current participant" seems reasonable. ${ }^{17}$ Nonetheless, the lack of an exact match on timing creates sufficient ambiguity to warrant sensitivity analyses. Alternate Classification 1, therefore, considers households in Category 4 to be non-participants, while Alternate Classification 2 treats them as missing. Category 5 consists of those who matched to caseload records, but the dates of SNAP receipt are not available. Again, since our goal with the baseline classifications is to capture current or recent participation, the lack of an exact date is not especially problematic, so we consider these households to be participators. However, if the

\footnotetext{
${ }^{17}$ We are grateful to Bruce Meyer and Nikolas Mittag for this observation.
} 
objective was to measure current participation, strictly speaking, the lack of an exact date would prevent any determination from being made, so Alternate Classification 3 treats these households as missing.

Turning to the ALERT variable in Table 3, households can fall into four different categories. Category 1 contains those for whom no match was attempted, or who did not match to the ADMIN data to provide a CASEID that would permit a deterministic match to the EBT ALERT database. We code these individuals as missing in our baseline classification. However, since most individuals for whom no match was attempted are likely true non-participants (as discussed in Section II), we code households in Category 1 as non-participants in Alternative Classification 3.

ALERT Categories 2 and 3 parallel those same numbered categories from the ADMIN data. Category 2 contains those for whom a match was attempted but not successful, indicating non-participation. Category 3 indicates a match to the EBT ALERT database was successful with date of last receipt within the 36-day window. Since the ALERT matches were probabilistic based on STOREID, amount, and date, it is conceivable that some of the Category 2 households may have failed to match due to reasons such as mistakes in the reported amounts and dates. Analogously, some of the Category 3 households may have been determined manually when a single FoodAPS transaction matched to multiple ALERT transactions. Thus, the final account number assigned to the FoodAPS transaction may result in an erroneous Category 3 determination. However, in our judgment such misclassification is unlikely to happen in more than a few cases, so we do not consider alternative classifications of ALERT Categories 2 and 3.

ALERT Category 4 households are similar to ADMIN Category 4 above; they matched to the EBT ALERT database, but the associated date of the last receipt is outside of the 36-day window. For similar reasons as mentioned above, we initially consider these households to be true 
participants, but Alternate Classification 1 considers them to be non-participants while Alternate Classification 2 treats them as missing.

Table 4 presents estimated participation and error rates for the various ADMIN and ALERT classification choices discussed above. Panel A uses the baseline classifications and the main sample that drops observations with missing values of either ADMIN or ALERT (under their baseline classifications) or any of the control variables. This enables an "apples-to-apples" comparison of the differences caused by ADMIN versus ALERT within the same sample. Panel $\mathrm{B}$ allows the sample size to vary depending on the treatment of missing data. The row labeled "ADMIN Baseline" in Panel B adds back in the observations with a valid value of that variable but missing "ALERT baseline," and vice versa. The rows for the alternate classifications can either contain more or fewer observations depending on the relative stringency of the criteria for handling ambiguous cases. For instance, the sample is much larger for "ALERT Alternate 3" than "ALERT Baseline" because the former treats the large number of households for whom no match was attempted (Category 1) as non-participants, whereas the latter considers them missing.

Panel A shows that the participation and misreporting rates in the main sample are broadly similar using the baseline constructions of ADMIN and ALERT. The estimated SNAP participation rate is $29 \%$ using ADMIN compared to $30 \%$ using ALERT. The false negative rates are 11.65 percent using ADMIN and 11.46 percent using ALERT, while the false positive rates are 8.39 percent using ADMIN and 7.83 percent using ALERT. Interestingly, for both participation measures, the prevalence of false negatives is substantially lower than previously reported by studies using more traditional survey datasets (Mittag, 2013; Meyer, George, and Mittag, 2015). One possible explanation is that FoodAPS households were asked to consent to having their responses verified. Even though all but 122 households gave consent, it is reasonable to presume 
that merely informing respondents about data verification and asking for consent may elicit more truthful responses and partly account for the lower estimated false negatives. Additionally, estimated false positives in the FoodAPS are much higher than typically found. Conceivably, individuals who were unsure whether or not their household received SNAP might have been more inclined to report affirmatively because of the looming verification.

Panel $\mathrm{B}$ documents considerable variation in participation and misreporting rates depending on the particular classification decisions for ADMIN and ALERT. The estimated participation rates for ADMIN vary from 23.75 percent (Alternate 1) to 28.59 percent for our baseline ADMIN classification choice, for a spread of 4.84 percentage points, or 20 percent of the lower end of the range. The ALERT classification choices lead to even more variability, ranging from about 24.14 percent (Alternate 3) to 33.51 percent for our baseline ALERT classification, for a spread of 9.37 percentage points, or 39 percent. The sensitivity in false negative rates is even more striking. For ADMIN, the estimated false negative rates vary from 6.83 percent (Alternate 2) to 13.23 percent (Alternate 3), meaning that judgment calls about classifications could potentially cause this rate to vary by up to $94 \%$. The false negative rates using ALERT range from 6.55 percent (Alternate 2) to 10.89 percent (Alternate 1), for a spread of $66 \%$. The false positive rate for ADMIN is less sensitive, ranging from a low of 6.75 percent (Alternative 1) to 8.08 percent in each of the other three cases, for a difference of 20 percent. For ALERT, the estimated false positives range from 7.04 percent (Alternative 1) to 12.17 percent (Alternative 3), for a more substantial spread of $73 \%$. Despite the considerable variation in these estimates, the finding that the false negative rate is notably lower in the FoodAPS than other surveys while the false positive rate is higher is nonetheless robust to all classifications. 


\section{B. Different Classification Choices for Combining ADMIN and ALERT}

This section introduces several approaches or ad hoc rules to consolidate the two administrative participation measures into a single "true" participation variable and then evaluates how these rules influence the estimated rates of SNAP participation and misreporting. For the rest of this section, ADMIN and ALERT refer to the baseline classification choices as described in Tables 2 and 3, respectively. We develop five decision rules to combine the administrative participation variables as follows:

1) Always use ADMIN unless missing. For households missing ADMIN data, their participation status is set to ALERT.

2) Always use ALERT unless missing. For households missing ALERT data, their participation status is set to ADMIN.

3) Drop if Disagreement: This rule sets the "true" participation variable to equal to both ADMIN and ALERT, only if they agree (i.e., if $\mathrm{ADMIN}=\mathrm{ALERT}=\mathrm{i}, \mathrm{i}=0,1$ ). When they disagree or if either of them is missing, the "true" variable is set to missing. This conservative approach will minimize errant classification but at a substantial cost to sample size.

4) More weight to matches: This rule is similar to (3) as it uses both ADMIN and ALERT if they agree. However, when they disagree, we set the "true" status to participation ("1"), unless either is missing in which case the "true" status is set to the value of the non-missing variable. In other words, this rule treats households as "true" participants if at least ADMIN or ALERT confirms participation. Otherwise, the household is considered a non-participant unless both are missing. 
5) More weight to non-matches: This rule is the reverse of (4). When ADMIN and ALERT disagree, we set the "true" status to non-participation ("0"), unless either is missing in which case the "true" status is set to the value of the non-missing variable. In other words, this rule treats households as "true" non-participants if at least ADMIN or ALERT confirms non-participation. Otherwise, the household is considered a participant unless both are missing.

Table 5 presents estimates of participation, false negative, and false positive rates under each of the above decision rules. The estimated participation rates range from 28.25 percent (Rule 3) to 34.81 percent (Rule 5). This is a spread of 6.56 , which represents $23 \%$ of the low end of the range. The estimated false negative rates range from 10.71 percent (Rule 5) to 12.28 percent (Rule 1), for a spread of 1.57 percentage points, or $15 \%$. The false positive rates vary quite substantially, from 4.53 (Rule 3) to 11.41 percent (Rule 5), for a spread of over 150\%. While our decision rules are by no means exhaustive, this exercise illustrates that how one chooses to resolve the ambiguity in the administrative variables has nontrivial consequences for estimated participation and reporting errors.

Some patterns also emerge. First, as expected, giving the benefit of the doubt to matches (Rule 4) leads to a relatively high estimated participation rate, and keeps the rate of false positives low but at the expense of a high rate of false negatives. The reverse is true when we give the benefit of the doubt to non-matches (Rule 5). Perhaps more surprising is that dropping cases where there is any ambiguity (ADMIN and ALERT disagree or either are missing; Rule 3) results in the lowest estimated participation rate, lowest rate of false positives, and second-lowest rate of false negatives. In other words, once we restrict the sample to households for whom the administrative measures are likely quite accurate, we see less disagreement with self-reported participation. There 
is a particularly large reduction in the number of cases in which the respondent reports participation but the administrative data disagree. This implies that some of the estimated misreporting observed under other decision rules is not actually misreporting at all, but instead reflective of flaws in the administrative variables. It is also noteworthy that the sample shrinks so much $-2,446$ to 1,898 , or $29 \%$ - under Rule 3, underscoring that the amount of ambiguity, and therefore scope for error, in the administrative measures is substantial.

\section{Preferred Approach to combining REPORT, ADMIN, and ALERT}

Given the ambiguity and sensitivity documented above, it is reasonable to ask whether linked administrative data can still be used to obtain insights beyond what could be done with selfreported information alone. The conservative Rule 3 should lead to a very accurate participation measure but at the cost of discarding nearly a third of the sample, which creates concerns about endogenous sample selection and external validity. The other decision rules avoid such a large reduction in same size but at the expense of accuracy. The goal of this section is to implement a more detailed strategy for combining ADMIN and ALERT that utilizes self-reports to help resolve ambiguous cases, with the goal of leveraging insights from all three measures to produce reliable estimates while preserving sample size. ${ }^{18}$

To motivate this approach, Table 6 presents information about the extent of disagreement among the three measures as well as the extent of missing data in each variable. ${ }^{19}$ Also, the last column reports how we classify disagreements into various categories for the purpose of

\footnotetext{
${ }^{18}$ This approach is similar in spirit to the FoodAPS' SNAPNOWADMIN variable discussed previously in footnotes 11 and 12. However, our method is more conservative in that it demands a higher level of agreement across the SNAP measures before considering the "true" value of participation non-missing.

${ }^{19}$ Note that there is essentially no missing data for self-reported participation: only out of 4,704 consenting households in the FoodAPS are missing this variable.
} 
developing our SNAP new participation variable, which we refer to as our "preferred" measure. There is about 63 percent agreement among all three measures (i.e., all three variables either indicate participation or non-participation), which we label as Category A. In Category B, making up about 10 percent of households, any two of the three measures agree while the third is missing. Category $\mathrm{C}$ respondents, which account for 5 percent, have both administrative measures agreeing but in conflict with the self-report. Households with only the self-reported participation variable who are missing both administrative measures (Category D) make up 12 percent, while the remaining 10 percent of respondents are lumped into miscellaneous types of disagreement in Category E.

The new, "preferred" measure of SNAP participation combines information from Categories A, B, and C and sets to missing observations in Categories D and E. For Category A, all three variables are in agreement, so we are comfortable setting the "true" participation variable equal to the associated value. For Category B, we are also comfortable making a determination since, although one variable is missing, the other two agree. For Category $\mathrm{C}$, we consider the selfreported participation value to be erroneous since it opposes both administrative measures, and there is no particular reason to expect errors in the administrative variables to be correlated with each other. This maintains the preference for administrative records if the information from those records appears to be reliable. Next, those in Category D have non-missing self-reported participation but are missing both administrative measures. We code their participation as missing given the established concerns in the literature about relying only on self-reports. Finally, we also set the participation status of respondents in Category E to missing. There are three types of Category E households: ADMIN and ALERT are non-missing but disagree, ADMIN and REPORT disagree while ALERT is missing, and ALERT and REPORT disagree with ADMIN 
missing. In such cases of explicit disagreement, a determination cannot be reached without establishing a rank ordering among the measures.

Ultimately, our preferred measure is non-missing for the entire main sample of 2,108 respondents. Relative to the sample sizes using the various decision rules in Table 5, this is less than the 2,446 observations obtained using decision rules that force an outcome even in ambiguous cases, but significantly larger than the 1,898 observations obtained under the conservative Rule 3 . The estimated participation rate using the preferred measure is 30.92 percent, which is slightly higher than those obtained using ADMIN and ALERT separately (Panel A in Table 4) but well within the ranges established by the various sensitivity checks in Tables 4 and $5 .^{20}$

\section{Econometric Analyses and Results}

We next turn to our regression estimates of the associations of SNAP with food insecurity, weight outcomes, and dietary healthfulness. This section's goal is to illustrate the sensitivity of these estimates to the assumptions, introduced in the previous section, about how to code ADMIN and ALERT separately as well as how to assign "true" participation in cases of disagreement between them. We do not attempt to address the endogeneity of participation because doing so with a single cross-section of data such as the FoodAPS is daunting, and our focus here is to examine measurement issues rather than identify causal effects. ${ }^{21}$ Negative selection into SNAP is

\footnotetext{
${ }^{20}$ The preferred SNAP participation measure leads to relatively low estimated rates of false negatives (8.53 percent) and false positives ( 3.99 percent), but this is by construction since the self-reported value is factored into the coding process.

${ }^{21}$ One approach to addressing the non-random selection into SNAP is relying on instrumental variables. Unfortunately, the usual state-level administrative policies used to study programs such as SNAP and WIC are not likely to be valid instruments with cross-sectional data as one would have to rely on variation across states. These program rules may be correlated with other state-level characteristics unrelated to participation decisions (see, e.g., Bitler, Currie, and Scholz, 2003; Bitler and Currie, 2005). As shown by Almada et al. (2016), non-classical measurement error can substantially alter IV estimates and cause them to fall outside of non-parametric upper bounds. Measuring SNAP participation as accurately as possible, therefore, would arguably be even more critical in in an IV context than in the OLS context shown here.
} 
well-documented in the literature, so our OLS estimates will likely be biased toward unfavorable outcomes (greater food insecurity, higher BMI and obesity rates, and less healthy diets), measurement issues aside.

Our regressions take the form

$$
y_{i s}=\beta_{0}+\beta_{1} S N A P_{i s}+\boldsymbol{\beta}_{2} \boldsymbol{X}_{i s}+\varepsilon_{i s}
$$

where $y_{i}$ is the outcome variable for individual/household $i$ (separate regressions for each of the outcomes discussed in Section II), $S N A P_{i}$ is an indicator of SNAP participation (separate regressions for each decision rule from Section III), $\boldsymbol{X}_{\boldsymbol{i}}$ is a vector of the control variables from Section II, and $\varepsilon_{i s}$ is the error term.

Measurement error in a binary variable is necessarily non-classical, so one cannot simply assume $\hat{\beta}_{1}$ to be biased toward zero (Kreider, 2010; Kreider et al., 2012; Nguimkeu et al., 2017). Measurement error in SNAP participation could potentially even lead the OLS estimator to be wrongly signed (Nguimkeu et al., 2017). It might be reasonable to suspect that some of the inconsistencies among the administrative measures, such as the inability to match names with sufficient certainty, are as good as random. However, other inconsistencies, such as appearing in the caseload records but not using an EBT card in the past 30 days, arise from personal choices and may, therefore, be correlated with the error term, hence leading to endogenous misclassification. ${ }^{22}$

We begin our presentation of the regression results with Table 7, which uses the main sample and compares OLS estimates (linear probability model if the outcome is binary) using REPORT, the baseline version of ADMIN (as described in Table 2), and the baseline version of

\footnotetext{
${ }^{22}$ Moreover, Bound, Brown, and Mathiowetz (2001) discuss the possibility that the measurement error may not be nondifferential, where measurement error is not independent of the outcomes of interest.
} 
ALERT (as described in Table 3). Similarly to Panel A of Table 4, the purpose here is to use a common sample to provide an apples-to-apples comparison of the results across the three measures. The first key result is that the results are qualitatively similar regardless of the SNAP participation measure used. As expected, SNAP participation is consistently associated with worse values of all six outcomes. Estimates for food insecurity and body mass index are significant at the $1 \%$ level for all three SNAP measures, while those for very low food security are never significant. Mild discrepancies are observed for HEI and obesity, as two of the estimates are significant at the $1 \%$ level while the third (using ALERT for HEI, ADMIN for obesity) is significant at the 5\% level. For severe obesity, the estimates for REPORT and ADMIN are significant at the 5\% level and 1\% level, respectively, while the estimate for ALERT is insignificant.

The magnitudes, however, are more sensitive to the choice of SNAP measure. The associations between SNAP and food insecurity range from 6 to 7 percentage points, for a 16.67 percent spread. The estimates for very low food security vary between 2 and 2.7 percentage points, or 35 percent. SNAP reduces HEI by between 1.3 and 2 units, for a sizeable 54 percent difference. The results for BMI only vary from 1.05 to 1.17 units, or $11 \%$, but greater sensitivity is observed for the dichotomous weight outcomes. The estimates for $\operatorname{Pr}($ Obese $)$ and $\operatorname{Pr}($ Severely Obese) range from 5.7 to 7.9 and 2.1 to 3.9 percentage points, respectively, for spreads of $39 \%$ and $86 \%$. Note also that the pattern of results is inconsistent with simple attenuation bias, in which case we would expect the magnitudes to be larger using the administrative SNAP measures than the self-report. For three of the outcomes the magnitudes are actually largest using self-reported participation, and in only one case is the magnitude using self-reported participation the smallest. This is consistent with the reporting error being non-classical (which can yield an expansion bias), but is also 
consistent with the administrative measures not being any more reliable than the self-report (i.e. there is some attenuation bias regardless of the measure used).

Table 8 presents similar OLS results using the self-reported participation and the eight classification choices described in Tables 2 and 3. The first row reports the estimates using the self-reported participation variable. The next eight rows use the different classification rules for coding ADMIN and ALERT separately. As in Table 7, for all outcomes the signs are robust across SNAP measures. However, there are some noteworthy differences in terms of significance levels and magnitudes. For instance, the association between self-reported SNAP participation and very low food security is a sizeable and statistically significant 4 percentage points. In contrast, the same association is never significant using any classification scheme for the administrative measures, and the magnitudes are much smaller: 0.2 to 2.3 percentage points. Recall from Table 7 that using the self-report also led to an insignificant result for very low food security for the common sample, meaning that much of the sensitivity observed here is actually from the difference in sample (i.e. adding back in 27 to 680 observations with non-missing self-reports but a missing value of one or both administrative measures depending on the administrative classification). This underscores the external validity concerns raised by the large amounts of missing data for the administrative variables.

The results for HEI and severe obesity are also quite sensitive. For HEI, the estimates using REPORT and ADMIN are large (-1.42 to -1.66 units) and significant, but they shrink considerably (-0.72 to -1.2$)$ using ALERT and are only significant in two of the four cases. Accordingly, the spread between the smallest and largest magnitude for HEI is over $130 \%$. For severe obesity, the estimates range from 4.5 to 5.2 percentage points using REPORT and ADMIN, but shrink to 1.2 
to 2.3 percentage points using ALERT and are always insignificant. The spread for severe obesity is therefore an enormous 333\%.

Finally, Table 9 presents regression results using the five decision rules discussed in Section III, Subsection B, as well as our preferred consolidation rule from Subsection C of Section III. Additionally, we consider a version of our preferred measure that imputes the missing values from Categories D and E. We perform multiple imputations under the assumption that the likelihood of missing data is correlated with observables but conditionally independent of unobservables, usually referred to as a "Missing at Random (MAR)" assumption. ${ }^{23}$

The first five rows show the results using the ad hoc decision rules, while the last two rows use our preferred measure both with and without imputation. Again, the signs are robust to the different SNAP measures, but there are important differences in significance levels and magnitudes. For instance, the association between SNAP and very low food security is significant and large (3.4 percentage points) using Rule 3 but insignificant in the other cases with a magnitude as small as 0.9 . The difference between the largest and smallest estimates is therefore $280 \%$. The estimate for HEI is usually significant and reaches as large as -1.69 units, but it is an insignificant -0.9 units under Rule 1, for a spread of $88 \%$. For severe obesity, significance levels are again mixed, with the estimates ranging from 2.1 to 4.7 percentage points (spread of $124 \%$ ).

Using the preferred measure, the results are very similar both with and without imputation. SNAP is predicted to increase the probabilities of being food insecure, having very low food security, being obese, and being severely obese by 6.7, 2.7, 7.2, and 4.5 percentage points, respectively. SNAP also increases BMI by 1.45 units and reduces HEI by 1.4 units. SNAP is significant at the $5 \%$ level or better for all outcomes except very low food security.

\footnotetext{
${ }^{23} \mathrm{We}$ implement the multiple imputation procedures using Stata's mi impute and mi estimate commands, with 50 multiply imputed samples.
} 
Summarizing, we find that the classification choices one makes with FoodAPS's three participation measures (REPORT, ADMIN, and ALERT) have important consequences not only for estimated participation and reporting error rates but also for the estimated associations between SNAP and food security, diet healthfulness, and weight outcomes. ${ }^{24}$ However, the different classification choices do not seem to matter for the signs of the estimated associations since they line up with our expectations if we suppose that participants are negatively selected.

\section{Conclusion}

This paper leverages the availability of self-reported and two different administrative measures of SNAP participation in the FoodAPS to investigate several issues related to SNAP and measurement error. We first present evidence that the two administrative SNAP variables suffer from considerable ambiguity and disagree with each other almost as much as they disagree with self-reported participation. We then demonstrate that different methods of coding the two administrative variables separately as well as various approaches to combining their resulting preferred versions into a single "true" participation measure can lead to meaningfully different estimated participation and misreporting rates. Next, we document similar sensitivity to assumptions about the administrative variables across ordinary least squares estimates of the associations of SNAP with food insecurity, body weight, and healthfulness of food purchases.

\footnotetext{
${ }^{24}$ In unreported results, we perform similar analyses by further restricting the sample to only primary respondents in State Group 1 as described in Section II. Recall that State Group 1 comprises 13 states where a one-to-one match was possible between ADMIN and ALERT data because they both contain the same case identifiers, thus, may be presumed to be more accurate. Overall, our main conclusions are unchanged. First, estimated participation and reporting error rates vary based on the classification choices. However, estimated false positives tend to be slightly smaller while false negatives tend to be slightly larger than those reported in Tables 4 and 5. Also, the pattern of results in Tables 7, 8, and 9 is similar when using only State Group 1 with a few differences. First, for Tables 8 and 9, the estimated associations using State Group 1 remain negative but are no longer statistically significant for diet healthfulness. Second, unlike in Table 7, the estimated associations for the probability of severely obese using ALERT are still positive but now statistically significant.
} 
Our work serves as a cautionary tale for using administrative records uncritically under the assumption that they represent the "gold standard" with regard to measurement. While some of the difficulties we observed with the linked administrative variables may be unique to FoodAPS, others likely generalize to other settings. For instance, challenges with obtaining data from all states and differences in data quality across states are hardly unique to SNAP caseload files, as many programs (such as Medicaid and public schools) are operated at the state or local levels and standards for data collection may differ across different geographic areas. Additionally, probabilistic matching between survey respondents and verified program participants would be necessary for other contexts as well since it is unlikely that both sources include universal identifiers such as social security numbers. Moreover, the fact that matches to EBT transaction data were not attempted for individuals who (perhaps erroneously) reported not participating in SNAP points to the broader tradeoff between rigor and budgetary/practical constraints during data collection. When faced with a choice between nationwide surveys and administrative records that are only available for certain areas or individuals and potentially flawed for others, it is not obvious that the administrative data are preferable.

With all that said, we do not stop at pointing out the flaws in administrative data. Instead, we propose a strategy to construct a single, "true" participation variable based on all available information from both administrative and self-reported measures. This allows us to obtain "preferred" results, both for participation rates and regression estimates. Similar strategies could potentially be utilized in other contexts as well.

Nonetheless, our study suffers from several limitations that should be addressed in future work. For instance, while we propose a method that intuitively should minimize measurement error, there is no way to directly test whether it indeed accomplishes that objective or whether 
other strategies could be superior. Additionally, we purposefully do not address endogenous SNAP participation because of inherent difficulties in pursuing standard IV methods with a single crosssection data with a relatively small sample size. Much is therefore left to be learned about both the impacts of SNAP and best practices for measurement when multiple flawed indicators of program participation are available.

\section{References}

Aigner, D. J. (1973). "Regression with a binary independent variable subject to errors of observation.” Journal of Econometrics, 1(1), 49-59.

Almada, L., McCarthy, I., \& Tchernis, R. (2016). What can we learn about the effects of food stamps on obesity in the presence of misreporting? American Journal of Agricultural Economics, 98(4), 997-1017.

Almada, L. \& Tchernis, R. (2016). Measuring effects of SNAP on obesity at the intensive margin. National Bureau of Economic Research Working Paper No. 22681.

Bitler, M. P., \& Currie, J. (2005). Does WIC work? The effects of WIC on pregnancy and birth outcomes. Journal of Policy Analysis and Management, 24(1), 73-91.

Bitler, M. P., Currie, J., \& Scholz, J. K. (2003). WIC eligibility and participation. Journal of Human resources, 38, 1139-1179.

Bound, J., Brown, C., \& Mathiowetz, N. (2001). Measurement error in survey data. Handbook of Econometrics, 5, 3705-3843.

Courtemanche, C., Carden, A., Zhou, X., and Ndirangu, M. (2015). Do big box grocers improve food security? Unpublished manuscript.

Courtemanche, C., Pinkston, J., Ruhm, C., and Wehby, G. (2016). Can changing economic factors explain the rise in obesity? Southern Economic Journal, 82(4), 1266-1310.

Currie, J. (2003). US food and nutrition programs, Means-tested transfer programs in the United States, pp. 199-290.

Denteh, A. (2017). The effect of SNAP on obesity in the presence of endogenous misreporting. Unpublished manuscript. 
Gundersen, C. \& Oliveira, V. (2001). The food stamp program and food insufficiency. American Journal of Agricultural Economics, 83, 875-887.

Gundersen, C. (2015). SNAP and Obesity, SNAP Matters: How Food Stamps Affect Health and Well Being.

Gregory, C., Ver Ploeg, M., Andrews, M., and Coleman-Jensen, M. (2013). Supplemental Nutrition Assistant Program participation leads to modest changes in diet quality. United States Department of Agriculture Economic Research Service Report No. 147.

Hofferth, S. L. (2004). Persistence and change in the food security of families with children, 19971999. E-FAN-04-001. Economic Research Service, U.S. Department of Agriculture. Available www.ers.usda.gov/publications/efan04001/

Hoynes, H. W., \& Schanzenbach, D. W. (2015). U.S. Food and Nutrition Programs. National Bureau of Economic Research Working Paper No. 21057.

Huffman, S. K. \& Jensen, H. H. (2003). Do food assistance programs improve household food security? Recent evidence from the United States. Working Paper 03-WP 335, Center for Agricultural and Rural Development, Iowa State University.

Kabbani, N. \& Wilde, E. (2003). Short Recertification Periods in the U.S. Food Stamp Program. Journal of Human Resources, 83, 1112-1138.

Kreider, B. (2010). Regression coefficient identification decay in the presence of infrequent classification errors. The Review of Economics and Statistics, 92(4), 1017-1023.

Kreider, B., Pepper, J. V., Gundersen, C., \& Jolliffe, D. (2012). Identifying the effects of SNAP (Food Stamps) on child health outcomes when participation is endogenous and misreported. Journal of the American Statistical Association, 107(499), 958-975.

Lewbel, A. (2007). "Estimation of average treatment effects with misclassification." Econometrica 75(2), 537-551.

Mabli, J., Ohls, J., Dragoset, L., Castner, L., \& Santos, B. (2013). Measuring the effect of Supplemental Nutrition Assistance Program (SNAP) participation on food security: Mathematica Policy Research.

Marquis, K. H., \& Moore, J. C. (2010). Measurement errors in SIPP program reports. Survey Methodology, 1.

Meyer, B. D., Mok, W. K., \& Sullivan, J. X. (2015). Household surveys in crisis. Journal of Economic Perspectives, American Economic Association, 29(4), 199-266.

Meyer, B. D., Goerge, R. \& Mittag, N. (2015). Errors in survey reporting and imputation and their effects on estimates of food stamp program participation. Unpublished Manuscript. 
Meyer, B.D. \& Mittag, N. (2018). Misreporting of government transfers: How important are survey design and geography? Unpublished manuscript.

Meyerhoefer, C. D. \& Pylypchuk, Y. (2008). Does participation in the food stamp program increase the prevalence of obesity and health care spending? American Journal of Agricultural Economics, 90(2), 287-305

Mittag, N. (2013). A method of correcting for misreporting applied to the food stamp program. US Census Bureau Center for Economic Studies Paper No. CES-WP-13-28.

Mittag, N. (2016). Correcting for misreporting of government benefits. IZA Discussion Paper No. 10266.

Nord, M. \& Prell., M. (2011). Food security improved following the 2009 ARRA increase in SNAP benefits. USDA, Economic Research Service, Economic Research Report No. 116.

Nguimkeu, P., Denteh, A., \& Tchernis, R. (2017). On the estimation of treatment effects with endogenous misreporting. National Bureau of Economic Research. No. w24117.

Schmidt, L., Shore-Shephard, L., \& Watson, T. (2016). The effect of safety net programs on food insecurity. Journal of Human Resources, 51(3), 589-614.

U.S. Department of Agriculture. (2012). Building a healthy America: A profile of the Supplemental Nutrition Assistance Program. Office of Research and Analysis, Food and Nutrition Service, U.S. Department of Agriculture.

Volpe, R., Okrent, A., \& Leibtag, E. (2013). The effect of supercenter-format stores on the healthfulness of consumers' grocery purchases. American Journal of Agricultural Economics, 95(3), 568-589.

Van Hook, J. \& Ballistreri, K.S. (2006). Ineligible parents, eligible children: Food stamps receipt, allotments and food insecurity among children of immigrants. Social Science Research, $35(1), 228-251$.

Wilde, P. \& Nord, M. (2005). The effect of food stamps on food security: A panel data approach. Review of Agricultural Economics, 27(3), 425-432. 
Table 1: Summary Statistics

\begin{tabular}{lc}
\hline Variable & Mean (Standard Error) \\
\hline SNAP Participation & \\
Self-reported (REPORT) & $0.32(0.02)$ \\
Administrative from caseload data (ADMIN) & $0.29(0.02)$ \\
Administrative from EBT transactions (ALERT) & $0.30(0.02)$ \\
\hline Dependent Variables & \\
Low food security & $0.20(0.02)$ \\
Very low food security & $0.13(0.01)$ \\
Total 2010 HEI score & $50.56(0.58)$ \\
Body mass index & $28.81(0.25)$ \\
Obese & $0.38(0.02)$ \\
Severely obese & $0.16(0.01)$ \\
\hline Control Variables & \\
Age (years) & $49.62(0.98)$ \\
Female & $0.71(0.02)$ \\
Black & $0.16(0.03)$ \\
White & $0.71(0.04)$ \\
Other race (non-black, non-white) & $0.13(0.02)$ \\
Married & $0.31(0.02)$ \\
Formerly married & $0.43(0.02)$ \\
Household size & $2.56(0.10)$ \\
Number of children & $0.93(0.07)$ \\
Rural tract & $0.33(0.06)$ \\
Less than high school education & $0.19(0.02)$ \\
High school graduate & $0.34(0.02)$ \\
Some college education & $0.21(0.01)$ \\
College degree or higher & $0.26(0.02)$ \\
Worked last week & $0.38(0.03)$ \\
Gross monthly family income (\$1000s) & $1.86(0.06)$ \\
Elderly at least 65 years present in HH & $0.61(0.02)$ \\
Never married & $0.28(0.03)$ \\
Miles from residence to primary food store & $0.26(0.02)$ \\
Primary food store is SNAP-authorized & $3.15(0.34)$ \\
Ne:Sys & $0.98(0.00)$ \\
\hline
\end{tabular}

Note: Statistics are from main analysis sample of 2108 observations. Observations are weighted to account for the complex sampling design of FoodAPS. 
Table 2: Possible Classifications for Administrative Participation Measure from Caseload Data (ADMIN)

\begin{tabular}{|c|c|c|c|c|c|c|}
\hline Category & Description & $\mathrm{N}$ & $\begin{array}{c}\text { Baseline } \\
\text { Classification }\end{array}$ & Alternate 1 & Alternate 2 & Alternate 3 \\
\hline 1 & ADMIN data not available from state & 448 & Missing & Missing & Missing & Missing \\
\hline 2 & $\begin{array}{l}\text { Match to caseload data attempted but did not } \\
\text { meet threshold for certainty }\end{array}$ & 1268 & $\begin{array}{l}\text { Non- } \\
\text { participant }\end{array}$ & $\begin{array}{l}\text { Non- } \\
\text { participant }\end{array}$ & $\begin{array}{c}\text { Non- } \\
\text { participant }\end{array}$ & $\begin{array}{l}\text { Non- } \\
\text { participant }\end{array}$ \\
\hline 3 & $\begin{array}{l}\text { Match confirms participation within } 32 \text { days of } \\
\text { the survey week }\end{array}$ & 763 & Participant & Participant & Participant & Participant \\
\hline 4 & $\begin{array}{l}\text { Match confirms participation more than } 32 \text { days } \\
\text { before the survey week or after the survey week }\end{array}$ & 134 & Participant & $\begin{array}{c}\text { Non- } \\
\text { participant }\end{array}$ & Missing & Participant \\
\hline 5 & $\begin{array}{l}\text { Match confirms participation but dates not } \\
\text { available }\end{array}$ & 175 & Participant & Participant & Participant & Missing \\
\hline
\end{tabular}

Note: Based on the main sample augmented with observations with missing ADMIN or ALERT but not any other variable.

Table 3: Possible Classifications for Administrative Participation Measure from EBT Transactions (ALERT)

\begin{tabular}{|c|c|c|c|c|c|c|}
\hline Category & Description & $\mathrm{N}$ & $\begin{array}{c}\text { Baseline } \\
\text { Classification }\end{array}$ & Alternate 1 & Alternate 2 & Alternate 3 \\
\hline 1 & $\begin{array}{l}\text { No acquisitions available for matching and no } \\
\text { match to ADMIN to provide CASEID }\end{array}$ & 574 & Missing & Missing & Missing & $\begin{array}{c}\text { Non- } \\
\text { participant }\end{array}$ \\
\hline 2 & $\begin{array}{l}\text { Match to ALERT data attempted but did not } \\
\text { meet threshold for certainty }\end{array}$ & 1174 & $\begin{array}{l}\text { Non- } \\
\text { participant }\end{array}$ & $\begin{array}{l}\text { Non- } \\
\text { participant }\end{array}$ & $\begin{array}{l}\text { Non- } \\
\text { participant }\end{array}$ & $\begin{array}{l}\text { Non- } \\
\text { participant }\end{array}$ \\
\hline 3 & $\begin{array}{l}\text { Match confirms participation within } 36 \text { days of } \\
\text { the survey week }\end{array}$ & 961 & Participant & Participant & Participant & Participant \\
\hline 4 & $\begin{array}{l}\text { Match confirms participation more than } 32 \text { days } \\
\text { before the survey week or after the survey week }\end{array}$ & 79 & Participant & $\begin{array}{l}\text { Non- } \\
\text { participant }\end{array}$ & Missing & Participant \\
\hline
\end{tabular}


Table 4: Estimated Participation and Misreporting Rates under Different Approaches to Using ADMIN and ALERT Separately

\begin{tabular}{lcccc}
\hline $\begin{array}{l}\text { Determination of final } \\
\text { ADMIN and ALERT status }\end{array}$ & Sample Size & $\begin{array}{c}\text { Participation } \\
\text { Rate (\%) }\end{array}$ & $\begin{array}{c}\text { False } \\
\text { Negative Rate } \\
(\%)\end{array}$ & $\begin{array}{c}\text { False Positive } \\
\text { Rate (\%) }\end{array}$ \\
\hline Panel A: Main Sample & 2108 & 29.00 & 11.65 & 8.39 \\
ADMIN Baseline & 2108 & 30.00 & 11.46 & 7.83 \\
ALERT Baseline & & & & \\
Panel B: Varying Samples & 2340 & 28.59 & 12.28 & 8.08 \\
ADMIN Baseline & 2340 & 23.75 & 11.70 & 6.75 \\
ADMIN Alternate 1 & 2206 & 24.96 & 6.83 & 8.08 \\
ADMIN Alternate 2 & 2165 & 25.55 & 13.23 & 8.08 \\
ADMIN Alternate 3 & 2214 & 33.51 & 10.49 & 8.64 \\
ALERT Baseline & 2214 & 29.73 & 10.89 & 7.04 \\
ALERT Alternate 1 & 2135 & 30.89 & 6.55 & 8.64 \\
ALERT Alternate 2 & 2788 & 24.14 & 10.49 & 12.17 \\
ALERT Alternate 3 & n & & & \\
\hline
\end{tabular}

Note: Observations are weighted to account for the complex sampling design of FoodAPS.

Table 5: Estimated Participation and Misreporting Rates under Different Approaches to Combining ADMIN and ALERT

\begin{tabular}{lcccc}
\hline \hline $\begin{array}{l}\text { Decision Rule when ADMIN and ALERT } \\
\text { Differ }\end{array}$ & $\begin{array}{c}\text { Sample } \\
\text { Size }\end{array}$ & $\begin{array}{c}\text { Particip- } \\
\text { ation Rate } \\
(\%)\end{array}$ & $\begin{array}{c}\text { False } \\
\text { Negative } \\
\text { Rate (\%) }\end{array}$ & $\begin{array}{c}\text { False } \\
\text { Positive } \\
\text { Rate (\%) }\end{array}$ \\
\hline Rule 1: Always use ADMIN unless missing & 2446 & 31.95 & 11.25 & 8.80 \\
Rule 2: Always use ALERT unless missing & 2446 & 32.30 & 11.10 & 8.31 \\
Rule 3: Drop if disagreement & 1898 & 28.25 & 10.98 & 4.53 \\
Rule 4: More weight to matches & 2446 & 34.81 & 11.57 & 5.46 \\
Rule 5: More weight to non-matches & 2446 & 29.44 & 10.71 & 11.41 \\
\hline
\end{tabular}

Note: Observations are weighted to account for the complex sampling design of FoodAPS. 
Table 6: Extent of Disagreement among SNAP Participation Variables

\begin{tabular}{|c|c|c|c|c|}
\hline REPORT & ADMIN & ALERT & Observations & Category \\
\hline 0 & 0 & 0 & 952 & A \\
\hline 0 & 0 & 1 & 11 & $\mathrm{E}$ \\
\hline 0 & 0 & . & 144 & B \\
\hline 0 & 1 & 0 & 21 & $\mathrm{E}$ \\
\hline 0 & 1 & 1 & 77 & $\mathrm{C}$ \\
\hline 0 & 1 & . & 12 & $\mathrm{E}$ \\
\hline 0 & . & 0 & 1 & B \\
\hline 0 & . & 1 & 9 & $\mathrm{E}$ \\
\hline 0 & . & . & 261 & $\mathrm{D}$ \\
\hline 1 & 0 & 0 & 74 & $\mathrm{C}$ \\
\hline 1 & 0 & 1 & 69 & $\mathrm{E}$ \\
\hline 1 & 0 & . & 18 & $\mathrm{E}$ \\
\hline 1 & 1 & 0 & 109 & $\mathrm{E}$ \\
\hline 1 & 1 & 1 & 795 & A \\
\hline 1 & 1 & . & 58 & B \\
\hline 1 & . & 0 & 17 & $\mathrm{E}$ \\
\hline 1 & . & 1 & 79 & B \\
\hline 1 & . & . & 81 & D \\
\hline
\end{tabular}

Note: Frequencies are based on the main sample augmented with observations with missing ADMIN or ALERT but not any other variable. 
Table 7: Regression Results using Each Participation Measure Separately

\begin{tabular}{|c|c|c|c|c|c|c|}
\hline & $\begin{array}{c}\text { Food } \\
\text { Insecurity }\end{array}$ & $\begin{array}{c}\text { Very Low } \\
\text { Food Security }\end{array}$ & $\begin{array}{l}\text { Healthy Eating } \\
\text { Index }\end{array}$ & $\begin{array}{l}\text { Body Mass } \\
\text { Index }\end{array}$ & $\overline{\text { Obese }}$ & Severely Obese \\
\hline Self-Reported & $\begin{array}{c}0.066^{* * *} \\
(0.020)\end{array}$ & $\begin{array}{c}0.027 \\
(0.018)\end{array}$ & $\begin{array}{c}-1.680^{* * *} \\
(0.615)\end{array}$ & $\begin{array}{c}1.045^{* * *} \\
(0.343)\end{array}$ & $\begin{array}{c}0.079 * * * \\
(0.024)\end{array}$ & $\begin{array}{c}0.039 * * \\
(0.018)\end{array}$ \\
\hline ADMIN Preferred & $\begin{array}{c}0.060 * * * \\
(0.020)\end{array}$ & $\begin{array}{c}0.022 \\
(0.018)\end{array}$ & $\begin{array}{c}-2.071 * * * \\
(0.601)\end{array}$ & $\begin{array}{c}1.166 * * * \\
(0.344)\end{array}$ & $\begin{array}{c}0.057 * * \\
(0.023)\end{array}$ & $\begin{array}{l}0.035^{*} \\
(0.018)\end{array}$ \\
\hline ALERT Preferred & $\begin{array}{c}0.070 * * * \\
(0.020)\end{array}$ & $\begin{array}{c}0.020 \\
(0.018)\end{array}$ & $\begin{array}{c}-1.292 * * \\
(0.605)\end{array}$ & $\begin{array}{c}1.114 * * * \\
(0.340)\end{array}$ & $\begin{array}{c}0.061 * * * \\
(0.023)\end{array}$ & $\begin{array}{c}0.021 \\
(0.019)\end{array}$ \\
\hline
\end{tabular}


Table 8: Regression Results using Each Participation Measure Separately

\begin{tabular}{|c|c|c|c|c|c|c|c|}
\hline & $\begin{array}{l}\text { Sample } \\
\text { Size }\end{array}$ & $\begin{array}{c}\text { Food } \\
\text { Insecurity }\end{array}$ & $\begin{array}{c}\text { Very Low } \\
\text { Food Security }\end{array}$ & $\begin{array}{c}\text { Healthy } \\
\text { Eating Index }\end{array}$ & $\begin{array}{l}\text { Body Mass } \\
\text { Index }\end{array}$ & Obese & $\begin{array}{c}\text { Severely } \\
\text { Obese }\end{array}$ \\
\hline Self-Reported & 2788 & $\begin{array}{c}0.059 * * * \\
(0.018)\end{array}$ & $\begin{array}{c}0.040^{* *} \\
(0.016)\end{array}$ & $\begin{array}{c}-1.500^{* * * *} \\
(0.541)\end{array}$ & $\begin{array}{c}1.272 * * * \\
(0.302)\end{array}$ & $\begin{array}{c}0.094 * * * \\
(0.021)\end{array}$ & $\begin{array}{c}0.043 * * * \\
(0.016)\end{array}$ \\
\hline ADMIN Preferred & 2340 & $\begin{array}{c}0.055^{* * *} \\
(0.019)\end{array}$ & $\begin{array}{c}0.019 \\
(0.017)\end{array}$ & $\begin{array}{c}-1.663 * * * \\
(0.569)\end{array}$ & $\begin{array}{c}1.328 * * * \\
(0.325)\end{array}$ & $\begin{array}{c}0.065 * * * \\
(0.022)\end{array}$ & $\begin{array}{c}0.048 * * * \\
(0.017)\end{array}$ \\
\hline ADMIN Alternate 1 & 2340 & $\begin{array}{c}0.056^{* * *} \\
(0.020)\end{array}$ & $\begin{array}{c}0.002 \\
(0.018)\end{array}$ & $\begin{array}{c}-1.484 * * \\
(0.577)\end{array}$ & $\begin{array}{c}1.202 * * * \\
(0.333)\end{array}$ & $\begin{array}{c}0.057 * * * \\
(0.022)\end{array}$ & $\begin{array}{c}0.045 * * \\
(0.018)\end{array}$ \\
\hline ADMIN Alternate 2 & 2206 & $\begin{array}{c}0.060 * * * \\
(0.020)\end{array}$ & $\begin{array}{c}0.012 \\
(0.018)\end{array}$ & $\begin{array}{c}-1.640 * * * \\
(0.597)\end{array}$ & $\begin{array}{c}1.377 * * * \\
(0.344)\end{array}$ & $\begin{array}{c}0.066 * * * \\
(0.023)\end{array}$ & $\begin{array}{c}0.051 * * * \\
(0.018)\end{array}$ \\
\hline ADMIN Alternate 3 & 2165 & $\begin{array}{c}0.053 * * * \\
(0.020)\end{array}$ & $\begin{array}{c}0.023 \\
(0.018)\end{array}$ & $\begin{array}{c}-1.417 * * \\
(0.599)\end{array}$ & $\begin{array}{c}1.249 * * * \\
(0.341)\end{array}$ & $\begin{array}{c}0.059 * * \\
(0.023)\end{array}$ & $\begin{array}{c}0.052 * * * \\
(0.019)\end{array}$ \\
\hline ALERT Preferred & 2214 & $\begin{array}{c}0.064 * * * \\
(0.019)\end{array}$ & $\begin{array}{c}0.023 \\
(0.018)\end{array}$ & $\begin{array}{c}-1.201 * * \\
(0.591)\end{array}$ & $\begin{array}{c}1.154 * * * \\
(0.333)\end{array}$ & $\begin{array}{c}0.064 * * * \\
(0.023)\end{array}$ & $\begin{array}{c}0.021 \\
(0.018)\end{array}$ \\
\hline ALERT Alternate 1 & 2214 & $\begin{array}{c}0.062 * * * \\
(0.020)\end{array}$ & $\begin{array}{c}0.009 \\
(0.018)\end{array}$ & $\begin{array}{l}-0.907 \\
(0.596)\end{array}$ & $\begin{array}{c}1.159 * * * \\
(0.335)\end{array}$ & $\begin{array}{c}0.065^{* * *} \\
(0.023)\end{array}$ & $\begin{array}{c}0.022 \\
(0.018)\end{array}$ \\
\hline ALERT Alternate 2 & 2135 & $\begin{array}{c}0.067 * * * \\
(0.020)\end{array}$ & $\begin{array}{c}0.016 \\
(0.018)\end{array}$ & $\begin{array}{c}-1.090 * \\
(0.608)\end{array}$ & $\begin{array}{c}1.218^{* * *} \\
(0.342)\end{array}$ & $\begin{array}{c}0.068 * * * \\
(0.023)\end{array}$ & $\begin{array}{c}0.023 \\
(0.019)\end{array}$ \\
\hline ALERT Alternate 3 & 2788 & $\begin{array}{c}0.052 * * * \\
(0.018)\end{array}$ & $\begin{array}{c}0.016 \\
(0.016) \\
\end{array}$ & $\begin{array}{l}-0.717 \\
(0.529) \\
\end{array}$ & $\begin{array}{c}1.133 * * * \\
(0.302)\end{array}$ & $\begin{array}{c}0.059 * * * \\
(0.021)\end{array}$ & $\begin{array}{c}0.012 \\
(0.017) \\
\end{array}$ \\
\hline
\end{tabular}


Table 9: Regression Results Combining Participation Measures through Various Rules

\begin{tabular}{|c|c|c|c|c|c|c|c|}
\hline & $\begin{array}{l}\text { Sample } \\
\text { Size }\end{array}$ & $\begin{array}{c}\text { Food } \\
\text { Insecurity }\end{array}$ & $\begin{array}{c}\text { Very Low } \\
\text { Food } \\
\text { Security }\end{array}$ & $\begin{array}{c}\text { Healthy } \\
\text { Eating Index }\end{array}$ & $\begin{array}{l}\text { Body Mass } \\
\text { Index }\end{array}$ & Obese & $\begin{array}{c}\text { Severely } \\
\text { Obese }\end{array}$ \\
\hline $\begin{array}{l}\text { Rule 1: Always use } \\
\text { ADMIN unless missing }\end{array}$ & 2446 & $\begin{array}{c}0.050 * * * \\
(0.019)\end{array}$ & $\begin{array}{c}0.022 \\
(0.017)\end{array}$ & $\begin{array}{l}-1.538 * * * \\
(0.558)\end{array}$ & $\begin{array}{c}1.352 * * * \\
(0.320)\end{array}$ & $\begin{array}{c}0.068 * * * \\
(0.021)\end{array}$ & $\begin{array}{c}0.047 * * * \\
(0.017)\end{array}$ \\
\hline $\begin{array}{l}\text { Rule 2: Always use } \\
\text { ALERT unless missing }\end{array}$ & 2446 & $\begin{array}{c}0.060 * * * \\
(0.019)\end{array}$ & $\begin{array}{c}0.02 \\
(0.017)\end{array}$ & $\begin{array}{l}-0.901 \\
(0.561)\end{array}$ & $\begin{array}{l}1.308 * * * \\
(0.316)\end{array}$ & $\begin{array}{l}0.070 * * * \\
(0.022)\end{array}$ & $\begin{array}{c}0.035 * * \\
(0.017)\end{array}$ \\
\hline $\begin{array}{l}\text { Rule 3: Drop if } \\
\text { disagreement }\end{array}$ & 1898 & $\begin{array}{c}0.075^{* * *} * \\
(0.021)\end{array}$ & $\begin{array}{c}0.028 \\
(0.019)\end{array}$ & $\begin{array}{l}-1.689 * * * \\
(0.652)\end{array}$ & $\begin{array}{c}1.297 * * * \\
(0.363)\end{array}$ & $\begin{array}{l}0.063 * * \\
(0.025)\end{array}$ & $\begin{array}{c}0.032 \\
(0.020)\end{array}$ \\
\hline $\begin{array}{l}\text { Rule 4: More weight to } \\
\text { matches }\end{array}$ & 2446 & $\begin{array}{c}0.061 * * * \\
(0.019)\end{array}$ & $\begin{array}{c}0.034 * * \\
(0.017)\end{array}$ & $\begin{array}{l}-1.482 * * * \\
(0.567)\end{array}$ & $\begin{array}{l}1.410 * * * \\
(0.316)\end{array}$ & $\begin{array}{l}0.071 * * * \\
(0.022)\end{array}$ & $\begin{array}{c}0.045 * * * \\
(0.017)\end{array}$ \\
\hline $\begin{array}{l}\text { Rule 5: More weight to } \\
\text { non-matches }\end{array}$ & 2446 & $\begin{array}{c}0.050 * * * \\
(0.019)\end{array}$ & $\begin{array}{c}0.009 \\
(0.017)\end{array}$ & $\begin{array}{l}-0.989 * \\
(0.558)\end{array}$ & $\begin{array}{l}1.276^{* * *} \\
(0.321)\end{array}$ & $\begin{array}{c}0.069 * * * \\
(0.021)\end{array}$ & $\begin{array}{c}0.038 * * \\
(0.017)\end{array}$ \\
\hline $\begin{array}{l}\text { Combined (SNAP- } \\
\mathrm{ABC} \text { ) }\end{array}$ & 2108 & $\begin{array}{c}0.069 * * * \\
(0.020)\end{array}$ & $\begin{array}{c}0.026 \\
(0.018)\end{array}$ & $\begin{array}{c}-1.298 * * \\
(0.607)\end{array}$ & $\begin{array}{c}1.475 * * * \\
(0.337)\end{array}$ & $\begin{array}{c}0.073 * * * \\
(0.023)\end{array}$ & $\begin{array}{c}0.043 * * \\
(0.018)\end{array}$ \\
\hline $\begin{array}{l}\text { Combined (SNAP- } \\
\text { ABC) with imputation }\end{array}$ & 2788 & $\begin{array}{c}0.067 * * * \\
(0.020)\end{array}$ & $\begin{array}{c}0.027 \\
(0.017)\end{array}$ & $\begin{array}{c}-1.401 * * \\
(0.626)\end{array}$ & $\begin{array}{c}1.447 * * * \\
(0.328)\end{array}$ & $\begin{array}{c}0.072 * * * \\
(0.023)\end{array}$ & $\begin{array}{c}0.045^{* *} \\
(0.018)\end{array}$ \\
\hline
\end{tabular}

Notes: Statistics based on the main sample augmented with observations with missing ADMIN or ALERT but not any other variable. Heteroscedasticity-robust standard errors are in parentheses. $* * *$ indicates statistically significant at the $1 \%$ level, $* * 5 \%, * 10 \%$. Observations are weighted to account for the complex sampling design of FoodAPS. 


\section{Appendix Table A1: 10-Question Food Security Question in FoodAPS}

\begin{tabular}{|c|c|}
\hline Question & Description \\
\hline E2 & In last 30 days, worried food would run out before we got more money \\
\hline E3 & Food ran out and had no money to buy more, in last 30 days \\
\hline E4 & Couldn't afford to eat balanced meals, in last 30 days \\
\hline E5 & $\begin{array}{l}\text { Adults skipped or cut size of meals b/c not enough money, in last } 30 \text { days }(\mathrm{Y} / \mathrm{N}) \\
\text { Universe: Answered "Sometimes not enough to eat" or "Often not enough to eat" } \\
\text { description of food sufficiency question within last } 30 \text { days, OR answered "Often } \\
\text { true" or "Sometimes true" to E2, E3 or E4. }\end{array}$ \\
\hline E5a & $\begin{array}{l}\text { Number of days adults skipped/cut meal size b/c not enough money, last } 30 \text { days } \\
\text { Universe: Answered "Yes" to E5 }\end{array}$ \\
\hline E6 & $\begin{array}{l}\text { Eat less than felt you should b/c not enough money, in last } 30 \text { days }(\mathrm{Y} / \mathrm{N}) \\
\text { Universe: Answered "Sometimes not enough to eat" or "Often not enough to eat" } \\
\text { description of food sufficiency question within last } 30 \text { days, OR answered "Often } \\
\text { true" or "Sometimes true" to E2, E3 or E4. }\end{array}$ \\
\hline E7 & $\begin{array}{l}\text { Ever hungry but didn't eat b/c not enough money, in last } 30 \text { days }(\mathrm{Y} / \mathrm{N}) \\
\text { Universe: Answered "Sometimes not enough to eat" or "Often not enough to eat" } \\
\text { description of food sufficiency question within last } 30 \text { days, OR answered "Often } \\
\text { true" or "Sometimes true" to E2, E3 or E4. }\end{array}$ \\
\hline E8 & $\begin{array}{l}\text { Lose weight b/c not enough money for food, in last } 30 \text { days }(\mathrm{Y} / \mathrm{N}) \\
\text { Universe: Answered "Sometimes not enough to eat" or "Often not enough to eat" } \\
\text { description of food sufficiency question within last } 30 \text { days, OR answered "Often } \\
\text { true" or "Sometimes true" to E2, E3 or E4. }\end{array}$ \\
\hline E9 & $\begin{array}{l}\text { Skip food all day b/c not enough money for food, in last } 30 \text { days }(\mathrm{Y} / \mathrm{N}) \\
\text { Universe: Answered "Yes" to E5, E5a, E6, E7, or E8. }\end{array}$ \\
\hline E9a & $\begin{array}{l}\text { How often adults skipped food all day b/c not enough money, in last } 30 \text { days } \\
\text { Universe: Answered "Yes" to E9 }\end{array}$ \\
\hline
\end{tabular}

